This item was submitted to Loughborough's Research Repository by the author.

Items in Figshare are protected by copyright, with all rights reserved, unless otherwise indicated.

\title{
Building services component reuse: a response to the need for adaptability
}

PLEASE CITE THE PUBLISHED VERSION

http://dx.doi.org/10.1177/014362440002100203

PUBLISHER

(c) Sage

VERSION

AM (Accepted Manuscript)

LICENCE

CC BY-NC-ND 4.0

REPOSITORY RECORD

Webb, Roy S., Derek S. Thomson, and John R. Kelly. 2019. "Building Services Component Reuse: A Response to the Need for Adaptability". figshare. https://hdl.handle.net/2134/9666. 
This item was submitted to Loughborough's Institutional Repository (https://dspace.lboro.ac.uk/) by the author and is made available under the following Creative Commons Licence conditions.

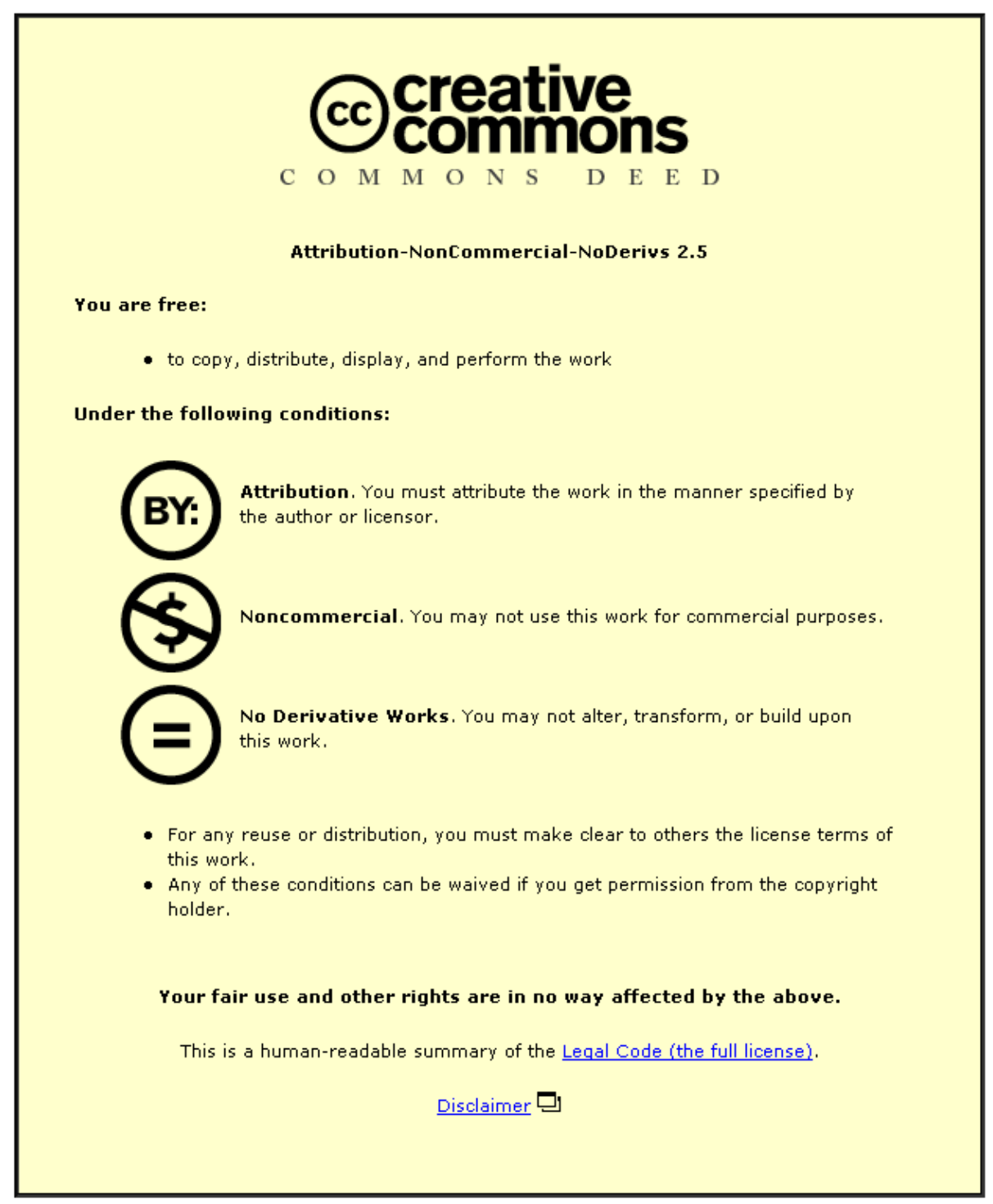

For the full text of this licence, please go to: http://creativecommons.org/licenses/by-nc-nd/2.5/ 


\title{
Building services component reuse: A response to the need for adaptability
}

\author{
R.S. Webb, D. S. Thomson, and J.R. Kelly
}

\begin{abstract}
As businesses become more dynamic, their need for supporting buildings providing flexibly usable space is growing. While such space can readily be constructed, its servicing remains problematic. Continued use of existing practice to alter services installations with increasing frequency is predicted to have detrimental whole-life cost and environmental consequences. The reuse of functionally obsolete services components has been proposed as a new, more adaptable, method of servicing buildings. Such component reuse will implement the proposal of the UK government, proposed in one of its 'Technology Foresight' reports, that standardised components be reused to increase the competitiveness of the UK construction industry. This paper summarises models developed by a recently completed pilot study to assess the technical and economic feasibility of component reuse. These models identify the potential viability of component reuse but also identified a number of issues requiring further, more detailed, investigation.
\end{abstract}

\section{Introduction}

As businesses operate in increasingly dynamic operating environments, they are maintaining their competitiveness by becoming more flexible [1]. Typically, this is being achieved by · flexibly performing core functions in the short term [2]. As a consequence, buildings supporting oftenchanging business functions must provide flexibly usable space [3]. While such space can be readily constructed [4], it is less easily serviced. Currently, difficulties in constructing adaptable services installations tend to be overcome by over-providing centralised plant [5-7] and floodfilling floor or ceiling voids with terminals. While this practice can accommodate future increases in servicing requirements, it has detrimental cost (capital and operating) consequences and environmental consequences.

\section{Provisions required for component reuse}

The predicted progressive reduction in their operating environments is causing businesses to become more flexible. As a result, the use made of their supporting buildings is changing with increasing frequency. This has allowed supporting buildings to be viewed as systemsC8.91, in which services installations inherit instability from their turbulent serviced spaces. As building users continue to become more dynamic, the stability of this system is progressively diminishing. The increasing dependency of business processes upon services provisions within their supporting buildings necessitates alteration of those services when the core business function of the building user changes. These alterations are characterised by revision of performance and of 
type or scope of servicing provisions, in addition to revision of their distribution among serviced spaces.

Individual services components are consequently tending to be installed in a given application for periods substantially less than their physical or economic life. This is causing services components to become functionally obsolete. The reuse of these components has been proposed $[10,11]$ as a way to increase services installation adaptability by recovering the value of residual component economic and physical life to reduce alteration costs. The design, procurement, installation and operation of components in a manner conducive to their future reuse is proposed to create 'packaged' reusable building services components. It is also proposed that organisational responsibilities be revised to facilitate component reuse. A new industry sector will recover functionally obsolete components from their current application, recondition them and guarantee them before their sale for reuse elsewhere. In addition, an information system will coordinate this new sector with building operators to overcome 'dutymatching' problems created by the extensive diversity of installed components. As a response to the need to service buildings in a manner that can readily accommodate change, the reuse of components as proposed above is preferred to the alternative association of adaptable distribution systems with centralised systems proposed by others $([12,13]$ which, by their nature, tend to be oversized and therefore inefficient.

This paper presents selected findings of a pilot study that investigated these issues and has recently been completed by the Department of Building Engineering and Surveying, Heriot-Watt University, Edinburgh, UK. This is the first study to investigate the possible implementation reuse of services components in response to the UK government's suggestion that the reuse of standardised components may increase the competitiveness of the construction industry [14].

\section{The implementation of widespread component reuse}

Many other industries already practise component reuse, including the offshore oil, the automobile after-sales and the office equipment industries [15]. Existing practices are characterised by their diversity. They vary from the simplistic, where reuse is facilitated by simple component repair and exchange, to the complex, where reuse is facilitated by remanufacturing. These varied practices were reviewed to identify those attributes appropriate to reuse of building services components. In addition, a questionnaire survey appraised the current extent of reuse of building services components[16]. A strategy for services component reuse was developed comprising three key elements:

- The 'packaging' of reusable building services components to possess physical attributes facilitating reuse. These include adequate maintainability and ease of isolation.

- A new industry sector, which will recover functionally obsolete components, recondition them and guarantee their future performance to facilitate component transfer between organisations for reuse. The skills delivered by this industry sector may be sourced from organisations who already recondition components within existing servicing and repair activities, such as original manufacturers. Additionally, new entrants may also develop and deliver appropriate skills from this industry sector. 
- An information system to match available, reconditioned, components with a purchaser's requirements.

A series of models predicted the viability of using the proposed 'packaged' reusable building services components to increase services installation adaptability. Two types of model determine the technical feasibility and economic viability of component reuse. As illustrated by Figure 1 technical models were constructed first, providing a framework for enumeration by corresponding economic models.

Two types of technical model were constructed to appraise the 'practicality' of component reuse:

- 'process stage models' to support organisations implementing a single stage of the proposed reuse strategy

- 'process role models' to support the revised function of organisations implementing component reuse.

All organisations will use a further technical model, the 'scrap or reuse' assessment, to determine the appropriateness of reusing a functionally obsolete component or whether it would more appropriately be discarded as scrap.

Two types of economic model predict the 'affordability' of component reuse:

- 'static models' predicting the cost of implementing a single reuse process stage

- 'dynamic models' predicting the whole-life cost implications of component reuse.

To justify the implementation of component reuse, a further economic model demonstrated the detrimental whole-life costs associated with continued use of existing practice to alter services installations with increasing frequency.

Because they appraise organisational function, technical models can be applied to any type of services component. Economic models, however, are currently specific to component type as many of their parameters are derived from component value. In addition, they are influenced by cost drivers such as the ability of functionally obsolete components to be retrofitted with current technology (to improve energy consumption, for example). To facilitate piloting, an example component was selected to provide economic parameters. A rotary heat exchanger represented air-handling plant because a questionnaire survey found that this type of component was currently reused most often by individual building operators [17]. Further studies will be required to generalise the economic models and facilitate their application to a range of component types.

\section{$5 \quad$ Modelling the technical feasibility of component reuse}

Models of the technical implications of component reuse serve two purposes:

- A limited number of these models define the proposed component reuse process by allocating new or revised responsibilities to implementing organisations.

- Most of these models provide decision support systems assisting revised organisation function. 
Two types of technical model fulfil these functions: technical process stage models and technical process role models.

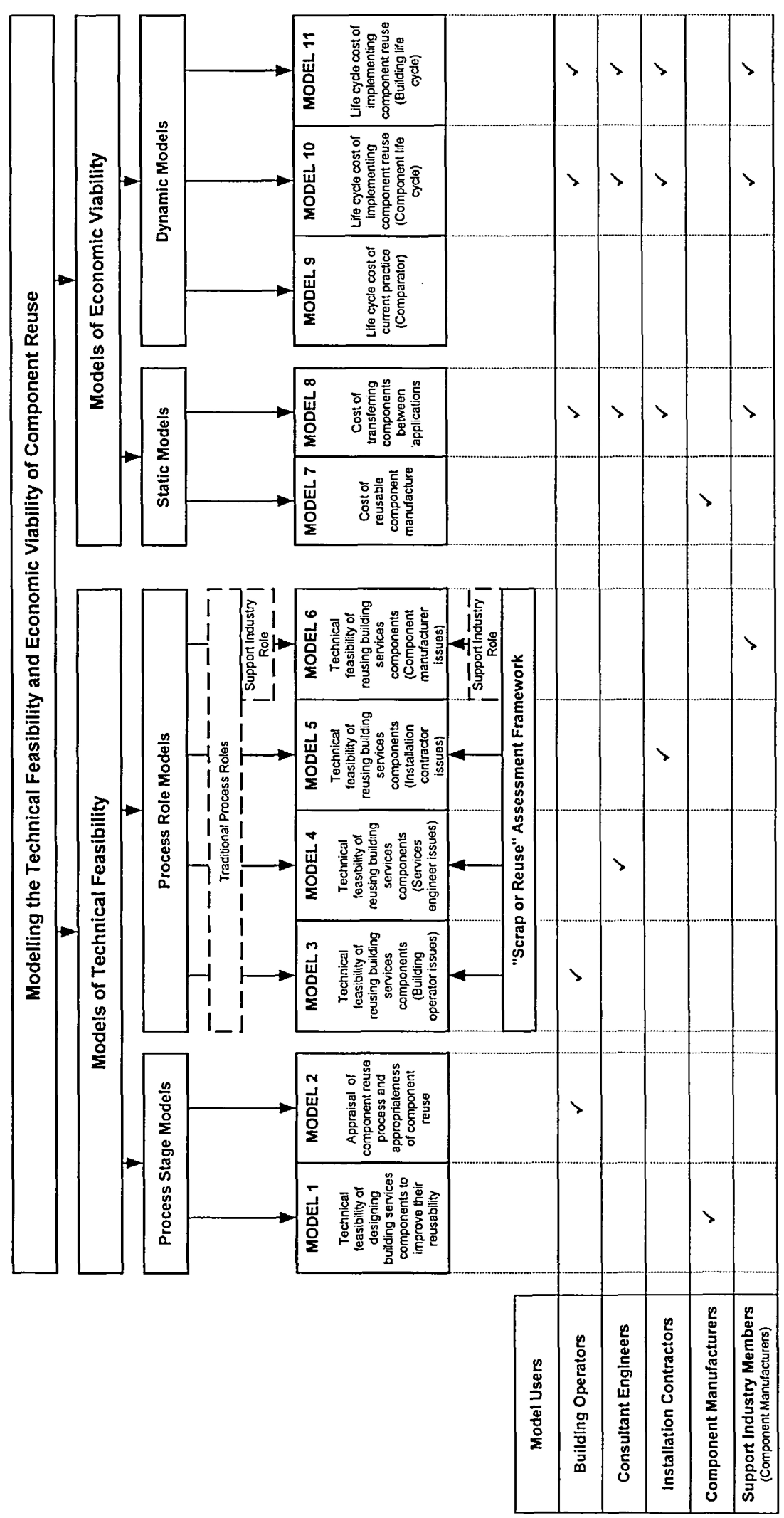

Figure 1: Relationship of models predicting the technical feasibility and economic viability of reuse of services components 


\subsection{Process stage technical models}

The first technical model will assist the design of more reusable building services components by providing a frame- work for the systematic review of existing designs and, by determining their inherent reusability, identifying the extent and type of design changes required to improve component reusability. The structure of this model is presented in Figure 2. The response to each decision is guided by a submodel of similar structure, appraising the topic of the question.

The model is presented as a matrix. The user starts at the top left corner and 'cascades' through the appraisal process. The appraised factors are ordered by their contribution to reusability so that the absence of such attributes will be identified early in the assessment, indicating low inherent reusability and negating the need for further appraisal. This model represents a preliminary understanding of the influence of physical attributes on reusability of components.

Through collaboration with component manufacturers, further studies must review the completeness and accuracy of this attribute ranking. This may identify the need to develop technical models for each component type, representing the differing extents to which their designs may be feasibly revised to improve reusability.

The second technical process stage model describes the component reuse process, from the recovery of functionally obsolete components to their installation in a new application. The extent to which existing organisational function must be revised will be established by the allocation of responsibilities to those organisations involved in this process. This model is presented in Figure 3.

The greatest number of reuse process stages will be implemented by the support industry members (represented by component manufacturers) and building operators. Consequently, these organisations must revise their function to the greatest extent. Two further models were constructed to sup- port building operators when altering services installations. The first will guide their appraisal of the appropriateness of reusing a functionally obsolete component within their own estate, while the second will guide their decision to purchase a component from the supporting industry to reuse it. 


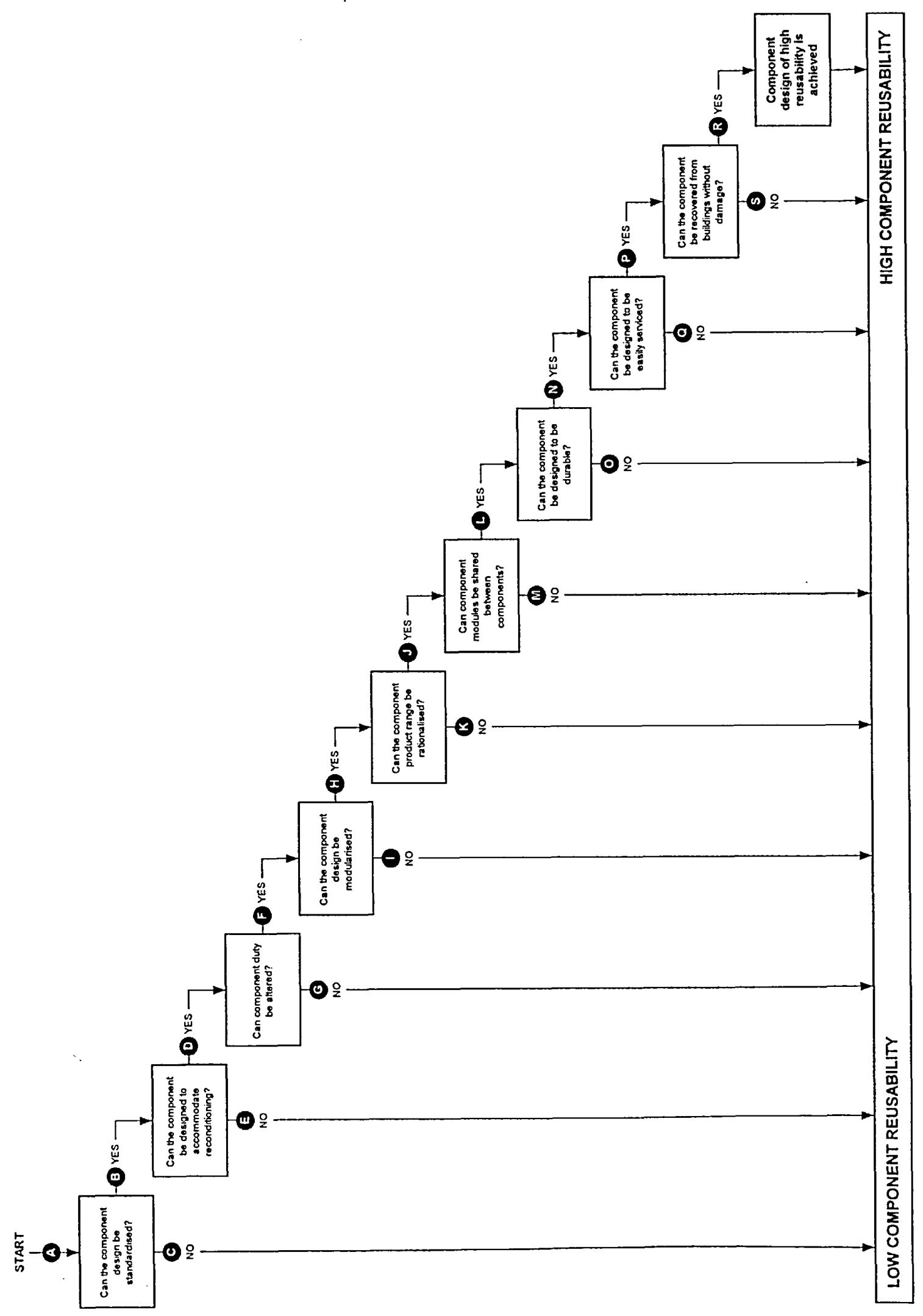

Figure 2: Technical process stage model appraising inherent component reusability 


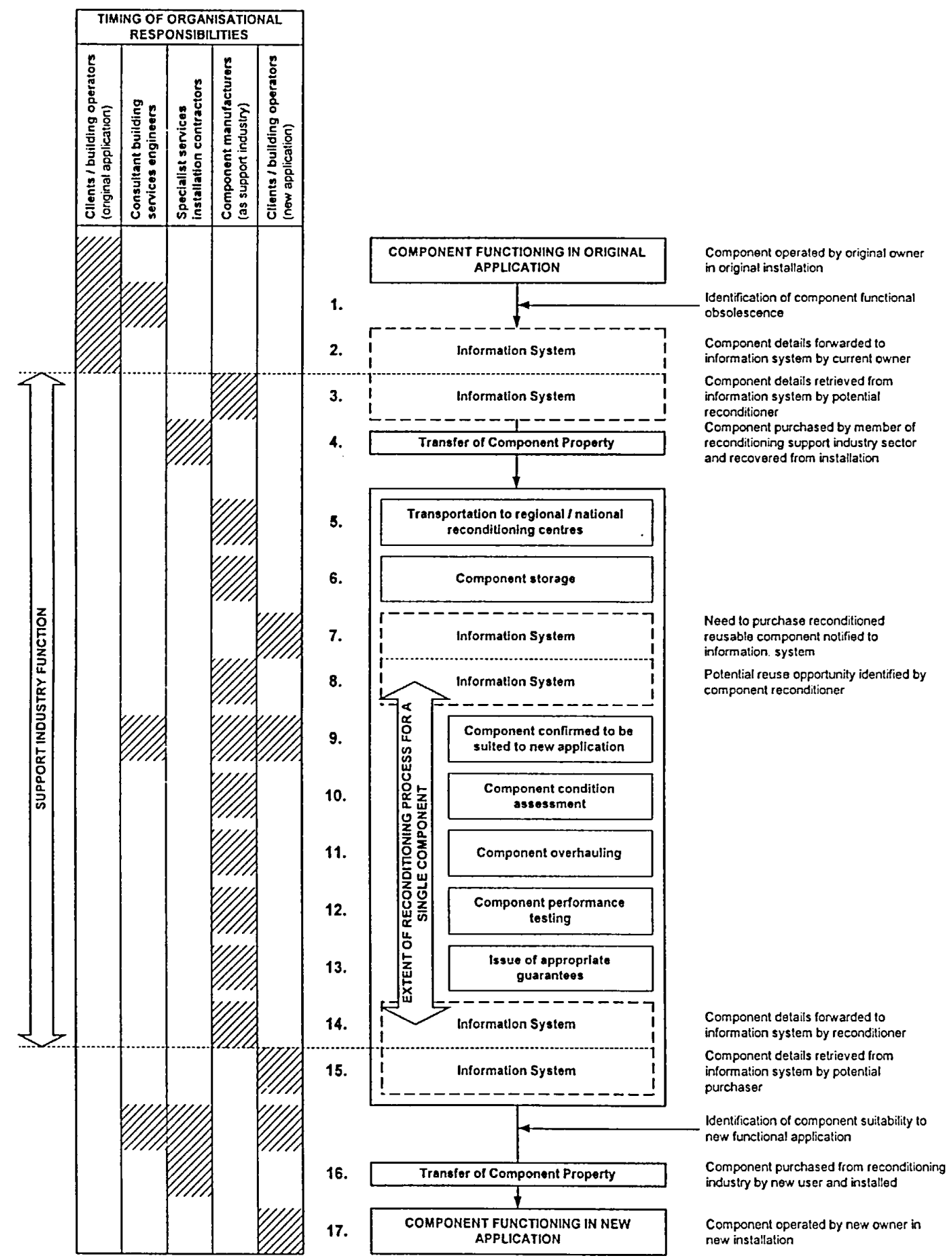

Figure 3: Structure of a single iteration of the component reuse process

\subsection{Process role technical models}

Four technical process role models were constructed to support the revised function of the four types of organisation (component manufacturers, installation contractors, consultant services engineers and building operators) predominantly responsible for reusing services components. Primarily, each organisation will decide when functionally obsolete component reuse is appropriate. Each technical process role model supporting these decisions addresses the context in which the decision will be made by each organisation type. Building operators will use their model to determine the appropriateness of forwarding a functionally obsolete component to the support industry for reconditioning. Consultant engineers will use their model to determine the 
appropriateness of specifying the reuse of a component sourced either from their client's estate or purchased from the support industry sector.

Finally, installation contractors will use their model to determine the appropriateness of proposing that a functionally obsolete component, or a reconditioned component sourced from the support industry, be reused.

Component manufacturers will not require a separate process role model as their revised activity will be adequately defined by the process stage technical models. The first technical process stage model will adequately support the manufacture of reusable components. When operating in the support industry, the second process stage model will adequately support their function.

\subsubsection{The scrap or reuse assessment framework}

Each of the above technical process role models incorporates a generalised 'scrap or reuse' assessment framework that will determine the appropriateness of reusing a functionally obsolete component. This decision is influenced by the following:

- the economic viability of component reuse the context in which the decision to reuse is made

- the ability of obsolete technology incorporated in the component to be upgraded

- previous reliability of the component

- the extent of inherent component reusability

- the avoidance of an unacceptable long lead time if purchasing a new component.

\section{Modelling the economic viability of component reuse}

Currently, component reuse usually occurs within the estate supporting individual organisations because building operators are uncertain of the economic viability and risk implications of exchanging components with other organisations for reuse [17]. While the strategy proposed for reuse will resolve the risk implications of that practice, it is necessary to demonstrate its economic viability via modelling to facilitate indus- trial implementation.

As discussed, the following economic model parameters were derived from the selling price of an example item of air- handling plant, selected to represent those components currently reused most often:

- maximum reusable component new selling price

- functionally obsolete component purchase price

- reconditioning process cost

- reconditioned reusable services component maximum selling price

Two types of economic model were constructed, classified by the duration of the time period they assessed [18]. 


\subsection{Static economic models}

Two static economic models, appraising short time periods, were constructed.

- A model predicting new reusable component selling ·price. Given that reusable components must possess reuse-enabling physical characteristics, this price was predicted to be greater than that of equivalent non- reusable components. At this piloting stage of proposal development, the cost of manufacturing a reusable component has not yet been determined. In the absence of detailed information provided by component manufacturers, a questionnaire survey of the organisations that will be involved in component reuse determined the price range at which a new reusable component could be sold, while remaining acceptable to them. Each reusable component price was expressed as a greater proportion of its non-reusable equivalent. It was assumed that the cost of manufacturing a reusable component would allow it to be sold at this price, but further work is required to validate this assumption.

- A model predicting the cost of component reuse. This model casted each stage of the reuse process, identified by second process role technical models, and provided data for a number of dynamic economic models.

\subsection{Dynamic economic models}

Three dynamic economic models were constructed.

- A model predicting the whole-life cost of altering service installations with increasing frequency using existing practice. By demonstrating the magnitude of these costs, this model identifies the need for a new approach to servicing buildings, thereby justifYing the proposal of services component reuse.

- A model predicting economic life of reusable components. Given an assumed programme of installation alteration, this model suggests that the economic life of a reusable component may exceed its physical life. Subsequent development of this model to permit its application to a range of component types and to validate its incorporated assumptions would clarifY this finding.

- A model predicting the whole-life cost consequences of reusing components when altering services installations. This model demonstrates that component reuse will reduce periodic expenditure on the alteration of services installations (compared to current practice). This con- firms that components can be reused to better manage the cash flow implications of services installation operation.

\section{Findings of an expert seminar}

Perceptions of the growing need to service buildings in a more adaptable manner and the proposal for component reuse, together with the models of its implications, were presented to industry representatives in an expert seminar. This event gauged likely industry response, allowing it to be anticipated by final project conclusions before their. dissemination throughout the UK construction industry. Hence, the expert seminar measured the 'completeness' of piloting work.

Delegates-agreed that there was a need to service buildings in a more adaptable way. The consequent proposal of component reuse was also accepted. The structure, objectives and 
preliminary findings of models constructed to predict the viability of reuse of services components were additionally accepted. Delegates stated, however, that the assumptions currently incorporated in these models must be validated by further studies before they would be sufficiently confident in model findings to instigate component reuse. This response was typical to that expected when considering the output of a pilot study.

The seminar concluded with agreement of a Statement of Intent, summarising its findings and setting the agenda for further investigation of component reuse:

'Attendees at an expert seminar hosted by the Department of Building Engineering and Surveying at Heriot- Watt University, and funded by the Engineering and Physical Sciences Research Council, believe that the development of reusable building services components may increase the adaptability of building services installations; an objective which is anticipated to become increasingly important to satisfY the needs of construction industry clients in the future. This work could be driven by:

- identifying the economic parameters of reuse

- investigating the opportunities for reuse created by establishing stronger links between clients and construction industry members through collaboration within the supply chain

- investigating the use of legislation or tax incentives as implementation mechanisms

- investigating the implementation of component reuse in a manner mutually beneficial to all parties and which does not prejudice continuing research and development for new components.'

\section{Conclusions and recommendations for further work}

This paper has reviewed the need for a 'more adaptable method of servicing buildings, necessitated by changing business functions and patterns of building use. Industry representatives have accepted this review, confirming its accuracy. The reuse of building services components has been proposed to increase services installation adaptability, and the technical and economic implications of this proposal have been anticipated by modelling. Component reuse has been selected for further investigation in preference to alternative methods of achieving installation adaptability as it was anticipated to offer the most efficient solution in turbulent operating circumstances. Modelling outcomes indicated that component reuse is likely to be viable. Further modelling is required, however, to validate incorporated assumptions and facilitate application to types of services component. Hence, there is a need for further work in this field.

Subsequent studies must investigate the following issues:

- identification of the physical attributes of components that contribute most to reusability and the viability of incorporating these components into packaged reusable component designs.

- predicting the cost of manufacturing reusable components that possess these attributes.

- identifYing aspects of component procurement practice and organisational responsibilities that also contribute to component reusability. 
- assuming that these more detailed studies will still demonstrate that component reuse will be viable, development of a strategy to integrate it into standard industry practice.

These further studies will require information best gathered $\sim \sim$ in collaborative studies with industrial partners.

\section{Acknowledgements}

This paper has presented findings from a pilot study carried out under UK Engineering and Physical Sciences Research Council award GR/LI6361 by the Department of Build- ing Engineering and Surveying, Heriot-Watt University, Edinburgh.

\section{References}

1. Genus A The management of change: perspectives and practice (London: International Thomson Business Press) (1998)

2. Volberda H W Building the flexible firm: how to remain competitive (Oxford: Oxford University Press) (1998)

3. Lizieri C, Crosby N, Gibson V, Murdoch Sand Ward C Right space: right price? - A study of the impact of changing business space patterns in the property market (London: The Royal Institution of Chartered Surveyors) (1997)

4. Bordass $W$ Building performance for the responsible workplace. The responsible.workplace: the redesign of work and offices Duffy F, Laing A and Crisp V (eds) (Oxford: Butterworth Architecture) pp 78-97 (1993)

5. Brittain J R J Oversized heating plant Guidance Note 12/97 (Bracknell: BSRIA) (1997)

6. Brittain J R J Oversized cooling and pumping plant Guidance Note13/97 (Bracknell: BSRIA) (1997)

7. Brand S How buildings learn: what happens after they're built (London: Viking Penguin) (1994)

8. Leaman A and Borden I The responsible workplace: user expectations The responsible workplace: the redesign of work and offices Duffy F, Laing A and Crisp V (eds) (Oxford: Butterworth Architecture) pp 16-32 (1993)

9. Webb R S, Kelly J R and Thomson D S Building services component reuse: an FM response to the need for adaptability Facilities 15(12/13) 316-322 (1997)

10. Webb R S, KellyJ R and Thomson D S Designing for short life: the emerging need for packaged reusable building services components in the UK healthcare sector Proceedings of the 15th International Congress of the International Federation of Hospital Engineering, Edinburgh (Portsmouth: The Institute of Hospital Engineering [now Institute of Healthcare Engineering and Estate Management]) pp 120-124 (1998)

11. Rutten P G S The adaptability of airconditioning systems Australian Refrigeration, Air Conditioning and Heating (Dec.) 43-51 (1989) 
12. Building Research Establishment Designing for adaptable building services (Building Research Establishment Indoor Environment Division: online http://www.bre.co.uk/ indoorenv/dabs.htm) (1999)

13. Office of Science and Technology Technology foresight: progress through partnership no. 2: construction (London:HMSO) (1995)

14. Webb R S, Kelly J R and Thomson D S Designing for short life: a study into the development of reusable packaged building services components in the healthcare sector Proceedings of the Cobra '97 Conference, University of Portsmouth (London: The Royal Institution of Chartered Surveyors) (1997)

15. Thomson D S, KellyJ R and Webb R S Attitudes to building services component reuse in the UK healthcare sector Facilities 16(12) 349-355 (1998)

16. Thomson D S, Kelly J R and Webb R S Designing for short life: industry response to the proposed reuse of building services components Proceedings of the Construction and Building Research Conference (COBRA) 1998, Oxford Brookes University, Oxford (London: The Royal Institution ofChartered Surveyors) volume 2 pp 122-132 (1998)

17. Sauter V L Decision support systems: an applied managerial approach (New York: Wiley) (1997) 